\title{
From Microscopes to Virtual Reality - How Our Teaching of Histology is Changing
}

\section{Michael Hortsch*}

Department of Cell and Developmental Biology, University of Michigan, USA

For a long time, histology has been a well-established, fundamental part of many biomedical curricula. As it provides a bridge from the macroscopic field of gross anatomy to the molecular sciences such as biochemistry, physiology and pharmacology, histology constitutes a central link between the visible and the submicroscopic dimension. In addition, by contrasting normal tissue structures and functions with changes seen under disease conditions it serves as a gateway to pathology. Histology as a scientific field and as an educational subject has always relied on technology, initially the introductions of reliable, high-quality light microscopes about 150 years ago. This enabled students and researchers to analyze tissues and cell structures at an increasingly smaller scale. The microscopic dimension and its reliance on visual information for the interpretation and understanding of tissue structure and function still provide major challenges for many students, who study histology for the first time. Over the last decade new technological advances have resulted in significant changes how we teach histology to our students [1-3]. One of which is the abandonment of traditional light microscopes in favor of digital histological images, referred to as "virtual microscopy" [4-9]. In this overview, I would like to use the experiences, which we made using virtual microscopy for teaching histology at the University of Michigan, to discuss the advantages and disadvantages, as well as future possibilities these new technologies provide to us for teaching a traditional subject to today's computer-savvy generation of students and how these students make increasing use of virtual microscopy and other electronic resources.

So why is the use of real light microscopes no longer "cool" for teaching histology? For many years, students have been studying sets of histological glass slides by regular light microscopy. However, the maintenance of a large number of student microscopes for teaching purposes and of sizeable collections of glass slides makes this approach a constant financial drain on any educational institution. As the quality of histological preparations is inherently variable and as glass, slides of many tissues, especially of human origin, are difficult or impossible to come by or to replace, this often results in great disparities between the learning resources that are available to individual students. On the positive side, students are required to learn the intricacies of manipulating a light microscope and to appreciate the variability of the biological material they have at their disposal. Over the last decade, more and more institutions of higher learning offer histology and pathology courses that partially or entirely rely on virtual microscopy as a main teaching tool [3]. Regular histological glass slides, which can be selected for quality of tissue preservation and histological staining, are scanned and converted into high-resolution digital images that are stored electronically on fast, high capacity computer servers. Students can access these images through local networks or the Internet and view them using regular computer monitors. As an example, the University of Michigan virtual histology slide collection is freely accessible through the Internet at http://histology.med.umich.edu. Appropriate software allows each student to select specific regions of interest on the slide, to zoom in and out and to move to other areas at their free choice. Like using Google Earth, only a small portion of the often Gb-size virtual image file is downloaded at a given time. This provides students with a viewing experience that is very comparable to real histological glass slides (Figure 1). In addition, every student in each class has equivalent access to the highest quality slide material. However, as a drawback, virtual microscopy delivers only a single plane of focus, thus lacking the vestige of three-dimensionality, which students can obtain using the fine focus knob of a regular microscope. In addition, virtual microscopy

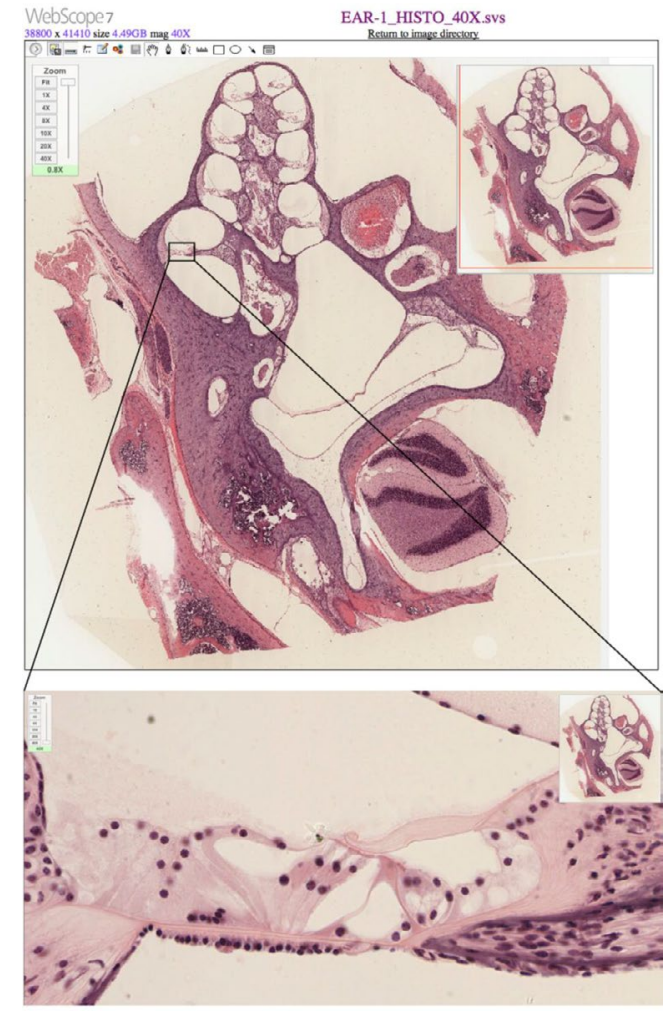

Figure 1: Shown is a screen capture of a virtual slide from the Michigan virtual slide collection that represents a histological section of the inner ear. The upper panel shows the entire section at $0.8 \mathrm{X}$ magnification whereas the lower panel depicts a segment with the organ of Corti at maximal magnification (40X).

http://141.214.65.171/Histology/Central\%20Nervous\%20System/EAR-1_ HISTO_40X.svs/view.apml

*Corresponding author: Michael Hortsch, Department of Cell and Developmental Biology, University of Michigan, 109 Zina Pitcher Place, Ann Arbor, MI 48109-2200, USA, E-mail: hortsch@umich.edu

Received June 26, 2013; Accepted July 01, 2013; Published July 03, 2013

Citation: Hortsch M (2013) From Microscopes to Virtual Reality - How Our Teaching of Histology is Changing. J Cytol Histol 4: e108. doi:10.4172/21577099.1000e108

Copyright: (c) 2013 Hortsch M. This is an open-access article distributed under the terms of the Creative Commons Attribution License, which permits unrestricted use, distribution, and reproduction in any medium, provided the original author and source are credited. 
relies heavily on a stable technological infrastructure that must accommodate multiple users accessing the same slide simultaneously and potential server outages. Most of today's students will gladly accept these limitations as they are freed from restrictive laboratory hours and are able to study histology and pathology at their own time schedule and from any location that provides server access.

At the University of Michigan, we started using virtual microscopy in combination with histological glass slides and regular microscopes for teaching medical histology during the academic year 2005/06. With the following year, medical students used predominantly virtual microscopy and were only offered sets of glass slides and a loan microscope upon request at the beginning of the histology component. Over the last 6 years, less than 10 out of over 1,000 students took advantage of this offer. As an alternative, we recently started setting up a number of demonstration microscopes with selected glass slides in one of the histology labs. Again, very few students regularly used this opportunity to compare histological slides viewed through real microscopes with the virtual images. Only 4 out of 142 students reported that they used the demonstration microscopes during every lab session, whereas 92 students indicated that they never used them over the

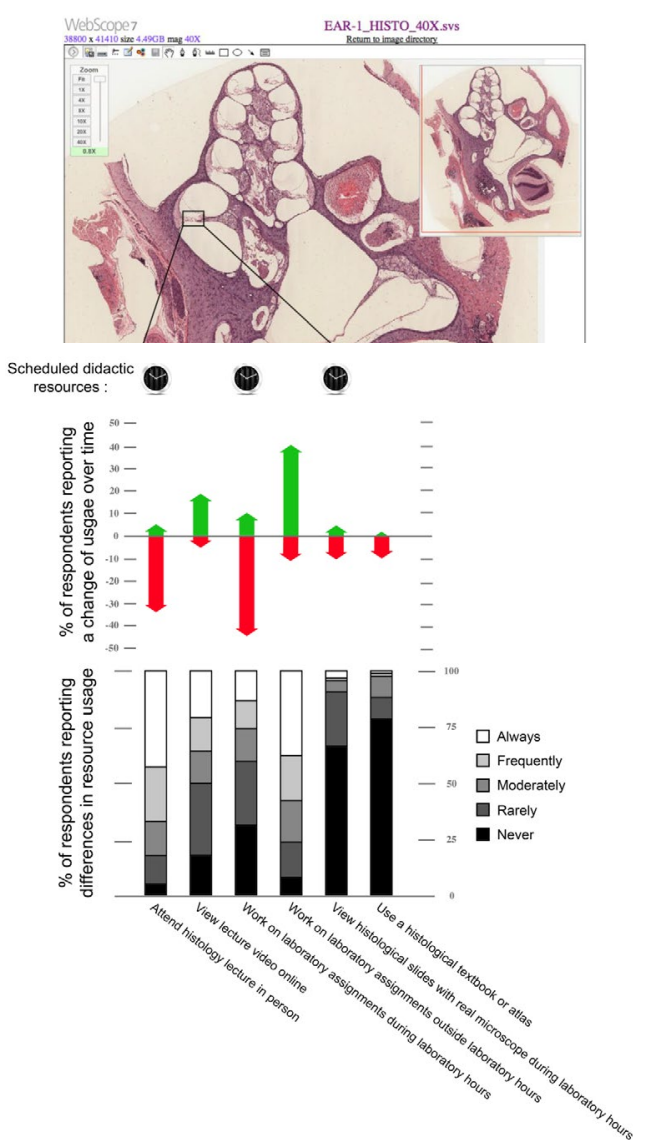

Figure 2: The figure is a graphic representation of responses from the Michigan Medical Class of 2015 to a survey about their use of various learning resources for histology that were offered during their first year of medical school (with the generous permission by Louisa Holaday, Daniel Selvig and Joel Purkiss). The clock marks didactic resources that were only offered at specific times, specifically lectures and laboratory sessions. The bottom panel indicates the reported frequency of usage for these different resources, whereas the red and green arrows indicate self-reported changes of over the academic year. 142 of a total of $167 \mathrm{M} 1$ students participated in the survey ( $85.6 \%$ response rate). entire M1 histology component (Figure 2, column 5). This choice of electronic technology over traditional approaches agrees well with the results of a recent study of student's resource use preferences to learn histology [10]. This study looked at the usage of various electronic and traditional histology-learning resources by the University of Michigan Medical School class of 2014. After the conclusion of the M1 histology component students were surveyed which educational resources they used to learn histology and how this usage changed over the academic year. Our study revealed two important tendencies exhibited by medical students learning histology. In general, most students preferred to study histology at their own time and scheduled resources, such as lectures and lab sessions, suffered a decreasing attendance as the academic year progressed. The second major finding showed a strong and growing preference to use a variety of electronic resources, not only virtual microscopy, but also lecture videos and supplemental histological PowerPoint series. Many traditional learning resources especially textbooks were used by very few students. It appears that the findings reported by Holaway et al. [10] and shown in Figure 2 reflect a general attitude of students studying histology.

However, not all traditional forms of teaching histology and pathology are rejected. Even though classroom attendance is declining over time, well over half of all Michigan M1 students elected to attend lectures regularly in person (Figure 2, column 1). Although recorded podcasts of lectures may be useful to clarify points a student might have missed during a live lecture presentation, a lack of image quality and the inherent unidirectionality of the teacher-student interaction usually make them an inferior learning experience.

With the introduction of new technologies such as virtual microscopy the question arises whether students' performance suffers ? Many studies that evaluated students' learning success in histology courses taught using virtual microscopy reported significant improvements in students' performance [11-14], whereas one looking at the graduate student level found no significant changes [15]. This indicates that when compared to the traditional, microscopebased approach of teaching histology, virtual microscopy is at least comparable, if not more effective for learning the structure-function relationship in tissues and organs at the microscopic scale. However, the knowledge of how to operate a regular light microscope is still a useful skill. This not only applies to the research environment, but also to some clinical settings, especially in practices and hospitals where digital technology is not yet available or to some routine procedures, such as in an OB/GYN practice [16].

However, the pace of change is not slowing down. On the contrary, new technologies that will help to teach the microscopic sciences are arriving with an ever increasing speed. One such type of gadget is iPad and Android-based computer tablets, which add an unsurpassed degree of portability and mobility to our students' ability to access information and educational material. With appropriate software, these devices enable students to study virtual slides and other histology material almost anywhere at any time. In addition, computer tablets will be excellent platforms for the development of novel interactive teaching tools that are highly valued by today's students. For example, we recently published a self-evaluation application for the iPad that is called "Michigan eHistology - A SecondLook ${ }^{\text {Tw }}$ Series" (http://www. med.umich.edu/lrc/secondlook/). In its original PowerPoint format this resource has been extremely popular with Michigan students studying histology for assessing their preparedness level before taking quizzes and exams [10]. The excellent image quality and ease of use make electronic tablets a superior tool for viewing virtual microscopic 
Citation: Hortsch M (2013) From Microscopes to Virtual Reality - How Our Teaching of Histology is Changing. J Cytol Histol 4: e108. doi:10.4172/2157$7099.1000 \mathrm{e} 108$

images and the development of new teaching strategies for histology, pathology and other biomedical fields.

The use of virtual microscopy is now an accepted and often integral part of teaching histology and pathology at many institutions of higher learning in the US and worldwide [3]. Most students appear to have enthusiastically embraced this change of teaching modus with no indication that their learning success has been compromised. When carefully used in the context of a coherent didactic program the advantages of adopting virtual microscopy and other electronic educational media clearly outweigh their limitations.

\section{References}

1. Coleman $\mathrm{R}$ (2009) Can histology and pathology be taught without microscopes? The advantages and disadvantages of virtual histology. Acta Histochem 111: $1-4$.

2. Drake RL, McBride JM, Lachman N, Pawlina W (2009) Medical education in the anatomical sciences: the winds of change continue to blow. Anat Sci Educ 2: 253-259.

3. Bloodgood RA, Ogilvie RW (2006) Trends in histology laboratory teaching in United States medical schools. Anat Rec B New Anat 289: 169-175.

4. Heidger PM Jr, Dee F, Consoer D, Leaven T, Duncan J, et al. (2002) Integrated approach to teaching and testing in histology with real and virtual imaging. Anat Rec 269: 107-112.

5. Krippendorf BB, Lough J (2005) Complete and rapid switch from light microscopy to virtual microscopy for teaching medical histology. Anat Rec B New Anat 285: 19-25

6. Patel SG, Rosenbaum BP, Chark DW, Lambert HW (2006) Design and implementation of a web-based, database-driven histology atlas: technology at work. Anat Rec B New Anat 289: 176-183.
7. Schmidt C, Reinehr M, Leucht O, Behrendt N, Geiler S, et al. (2011) MyMiCROscope: intelligent virtual microscopy in a blended learning model at Ulm University. Ann Anat 193: 395-402.

8. Weaker FJ, Herbert DC (2009) Transition of a dental histology course from light to virtual microscopy. J Dent Educ 73: 1213-1221.

9. Bloodgood RA (2012) Active learning: A small group histology laboratory exercise in a whole class setting utilizing virtual slides and peer education. Anat Sci Educ 5: 367-373.

10. Holaday L, Selvig D, Purkiss J, Hortsch M (2013) Preference of Interactive Electronic Versus Traditional Learning Resources by University of Michigan Medical Students During the First Year Histology Component. Med Sci Educator 23.

11. Husmann PR, O'Loughlin VD, Braun MW (2009) Quantitative and qualitative changes in teaching histology by means of virtual microscopy in an introductory course in human anatomy. Anat Sci Educ 2: 218-226.

12. Kumar RK, Freeman B, Velan GM, De Permentier PJ (2006) Integrating histology and histopathology teaching in practical classes using virtual slides. Anat Rec B New Anat 289: 128-133.

13. Lei LW, Winn W, Scott C, Farr A (2005) Evaluation of computer-assisted instruction in histology: effect of interaction on learning outcome. Anat Rec $B$ New Anat 284: 28-34.

14. Higazi TB (2011) Use of interactive live digital imaging to enhance histology learning in introductory level anatomy and physiology classes. Anat Sci Educ 4: 78-83.

15. Triola MM, Holloway WJ (2011) Enhanced virtual microscopy for collaborative education. BMC Med Educ 11: 4.

16. Pratt RL (2009) Are we throwing histology out with the microscope? A look at histology from the physician's perspective. Anat Sci Educ 2: 205-209. 